Results: A total of 260 patients took part in the survey; mean age of the respondents was 60 years IQR (54-66), 93\% were female. In July $202088 \%$ of patients had accessed a telemedicine-based and $12 \%$ a face-to-face rheumatology consultation; only $3.5 \%$ of patients reported having been less adherent to pharmacological therapy due to information received through media or social networks. Regarding the prevention measures taken during the pandemic, 98\% reported to have stayed in their houses since the lockdown was stablished in Colombia, and have implemented or increased hand washing from one or none to more than three times per day. Also $8 \%$ of respondents lived with people who were at bigger risk of having SARS-CoV-2 (i.e. health care professionals, workers at public transportation, and supermarkets among others), the main measurement taken was to be completely separate from the person at risk to avoid contagion and maintaining hygiene measures and physical distancing (Fig 1). Only one patient was positive for SARS-CoV-2, due to a possible contagion from a relative at home and reported only flu-like symptoms without any complications. Patients highlighted the necessity to return to the educational on RA program agreeing to attend to an online modality. Patients highlighted the need for educational sessions focused on the relationship between rheumatoid arthritis, its treatment, and Covid-19.

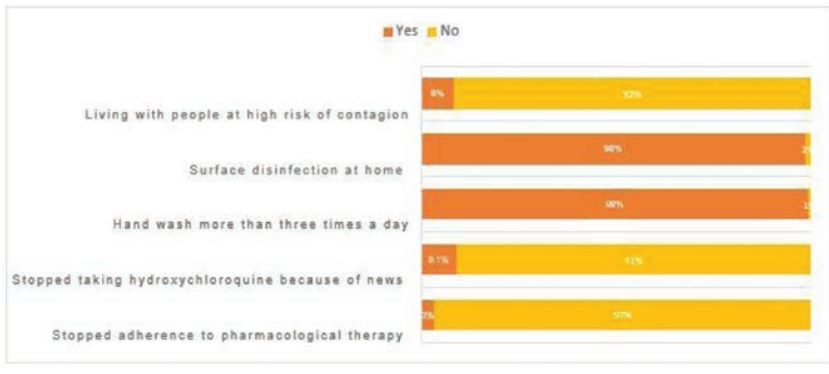

Figure 1. Behaviors, practices, and its changes due to Covid-19 pandemic

Conclusion: An educational on RA program shows to be helpful tool to maintain high adherence rates to the RA treatment despite of the new challenges associated to the pandemic and despite being incomplete due to lack of time; patient-centered education programs should continue to address the patient's concerns and beliefs about their disease and the Covid-19 issues.

Disclosure of Interests: Fernando Rodriguez: None declared, Diana Buitrago-Garcia: None declared, GUILLERMO SÁNCHEZ: None declared, Pedro Santos-Moreno Speakers bureau: Pedro Santos-Moreno has received fees for conferences from: Abbvie, Abbott, Biopas-UCB, Bristol, Janssen, Pfizer, Roche, Sanofi., Consultant of: Pedro Santos-Moreno has received fees for counseling and advisory boards from: Abbvie, Abbott, Biopas-UCB, Bristol, Janssen, Pfizer, Roche, Sanofi., Grant/research support from: Pedro Santos-Moreno has received esearch grants from: Abbvie, Biopas-UCB, Bristol, Janssen, Pfizer, Roche, Sanofi.

DOI: 10.1136/annrheumdis-2021-eular.3434

\section{AB0922-PARE OSTEOPOROSIS AWARENESS LEVEL AS A METHOD FOR IMPROVING PRIMARY PREVENTION}

S. Lezhenina ${ }^{1}$, A. Lammert2, N. Shuvalova ${ }^{3}$, E. Guryanova ${ }^{4} .{ }^{1}$ I. N. Ulianova Chuvash State University, Departament of Healthcare Management and Economics, Cheboksary, Russian Federation; ${ }^{1}$ I. N. Ulianova Chuvash State University, Departament of Healthcare Management and Economics, Cheboksary, Russian Federation; ${ }^{3}$ I. Ya. Yakovlev Chuvash Pedagogical State University, Department, Cheboksary, Russian Federation; ${ }^{4}$ I. N. Ulianova Chuvash State University, Department internal diseases, Cheboksary, Russian Federation

Background: Having complete information about osteoporosis is a prerequisite for preventive behavior, which determines the conscious adherence to the principles of a healthy lifestyle.

Objectives: To assess the level of awareness of osteoporosis among women. Methods: A survey was conducted of 750 female respondents aged 15 to 55 years in the Chuvash Republic. The survey was conducted from January to December 2019. The questionnaire consisted of 30 questions. One point was awarded for each correct answer. The minimum score for passing the test was $75 \%$ correct answers. The questions addressed both general knowledge about osteoporosis and the relationship between disease onset and diet, physical activity, vitamin $\mathrm{D}$, cigarette smoking, excessive alcohol consumption, and being overweight. The respondents were divided into two groups: group $A(n=375)$ - females from 15 to 35 years old and group $B(n=375)$ - females from 36 to
55 years old. Survey data was processed in Statistical Analysis Software 15.0. Statistical significance was calculated using Analysis of Variation.

Results: We obtained the following results for the Main Aspects of the survey: 1 Osteoporosis is a rare condition that occurs primarily in women (Awareness level: Group A - 47\%; Group B - 67,5\%; Analysis of Variation > 0,05). 2. Postmenopausal women are more at risk of osteoporosis (Awareness level: Group A - 73,5\%; Group B - 70,4\%; Analysis of Variation > 0,05). 3. Prevention of osteoporosis is impossible (Awareness level: Group A - 78,8\%; Group B - 89\%; Analysis of Variation $>0,05)$. 4. Vitamin $D$ is synthesized by direct exposure to $U V$ radiation on the skin (Awareness level: Group A - 53,1\%; Group B - 69,1\%; Analysis of Variation $>0,05)$. 5. Effective prevention of osteoporosis are: I. Balanced diet; II. Absence of bad habits; III. Occupation with health-improving physical culture. IV. Reduction of excess body weight (Awareness level: Group A - 69,2\%; Group B $47,1 \%$; Analysis of Variation $>0,05$ ). 6 . Increased consumption of table salt, sugar and excessive consumption of protein foods, vegetarianism negatively affects the quality of bone tissue (Awareness level: Group A - 56,7\%; Group B - 70,4\%; Analysis of Variation $>0,05$ ).

Conclusion: The conducted survey shows that the level of awareness of osteoporosis and its prevention is low among women in different age groups. In some cases, it is even a cause for concern. We believe that respondents' statements that osteoporosis cannot be effectively prevented are the most important findings of our study. Starting from adolescence, women should be well aware of the main risk factors for the development of osteoporosis, the mechanisms of its development and its consequences. This knowledge will help substantiate why it is necessary to lead a healthy lifestyle, which will help to prevent the development of this disease in the future. The concept of prevention of osteoporosis should include the following recommendations for the general population: to maintain a physically active lifestyle and to spend sufficient time under the influence of sunlight, avoid smoking and drinking large amounts of alcohol, ensure that dietary calcium intake is in line with the recommended level in the area, and maintain an appropriate body weight.

Disclosure of Interests: None declared

DOI: 10.1136/annrheumdis-2021-eular.3856

\section{Building patient led organisations}

\section{AB0923-PARE WHAT IS THE IMPACT ON THE QUALITY OF LIFE (QOL) OF PEOPLE LIVING WITH SPONDYLOARTHRITIS $\left(\mathrm{SPA}^{*}\right)$ ?}

S. Patenaude ${ }^{1}$, W. Gerhart ${ }^{2} .{ }^{1}$ Canadian Spondylitis Association, Intern, Phelpston, Canada; ${ }^{2}$ Canadian Spondylitis Association, Executive Director, Phelpston, Canada

Background: SpA describes a group of chronic inflammatory arthritic diseases with common features including inflammation of the spine, eyes, skin and gastrointestinal tract. These conditions can be painful and debilitating for many. Delayed diagnosis and treatment can lead to irreversible damage to the spine and other joints. Diagnosis of these conditions can take, on average, 7 years or more. We don't know what causes SpA and there is no cure. The onset of symptoms can be in early childhood and expands throughout one's lifespan. It affects children, women and men worldwide.

Objectives: To understand how living with $\mathrm{SpA}$ impacts $\mathrm{QOL}$ (including relationships, work and day-to-day life) and what is important to patients in order to help the $\mathrm{CSA}^{\star *}$ prioritize advocacy focus and resource development.

Methods: The CSA surveyed the community virtually from $11 / 19 / 19$ to $01 / 21 / 20$. The results of 838 respondents were analyzed after the survey closed.

Results: $66 \%$ of respondents had been diagnosed with Ankylosing Spondylitis and $24 \%$ with Psoriatic Arthritis. $22 \%$ were diagnosed with more than one form of SpA.

Over $70 \%$ reported their day-to-day life was negatively impacted by SpA. Only $7 \%$ indicated no impact on their daily life and $22 \%$ said it was somewhat impacted. Ability to remain in the workplace was impacted and $16 \%$ reported being on long-term disability and $4 \%$ on short-term disability. There were $7 \%$ who retired early due to their disease.

Sleep loss/interruption was reported by $89 \%$ and $74 \%$ said they avoid social events. $41 \%$ of participants are highly restricted by SpA when it comes to tasks like outdoor yard work. Other highly restricted tasks include exercise $(36 \%)$ and cleaning (31\%). Tasks of medium restriction include preparing meals $(31 \%)$ and engaging in intimate relations $(30 \%)$.

Upon diagnosis and disease progression, many reported less frequent participation in exercise, travel, intimate relationships, social outings and family activities. Some even said they stopped participating in these all together.

When asked to rank what was most important regarding QOL, most ranked living with no/reduced pain as most important, followed by improved sleep/no fatigue. The least important were returning to work and going out with friends. 